\title{
Efficacy and Safety of Tranexamic Acid in Total Knee Replacement Surgeries: A Randomized Control Trial
}

\author{
${ }^{1}$ Madhavi Buddhi, ${ }^{2}$ Disha Kapadia
}

\begin{abstract}
Context: Bleeding is of utmost concern in major orthopedic operations like total knee replacement, total hip replacement, and spine surgeries. Strategies to reduce blood loss must be employed to reduce allogeneic blood transfusion. Tranexamic acid (TAX) is an inexpensive synthetic derivative of the amino acid lysine. By attaching to lysine binding sites on plasminogen molecules it forms tranexamic acid-plasmin complex which has weaker fibrinolytic properties than plasmin alone. It also exhibits clot stabilizing and anti-inflammatory properties. When administered to surgical patients it can reduce blood loss and thus decrease transfusion requirements.
\end{abstract}

Aim: This is a study to evaluate the efficacy and safety of tranexamic acid in reducing blood loss and need of postoperative blood transfusions following unilateral total knee replacement surgery in a tertiary care teaching hospital.

Materials and methods: Sixty patients, $18-70$ years, American Society of Anesthesiology (ASA) statuses I and II undergoing unilateral total knee replacement under combined spinal-epidural anesthesia were enrolled in this prospective, randomized, double-blind study. Thirty patients each were randomly assigned to group T (TAX) and group C (control). Group T received intravenous tranexamic acid $10 \mathrm{mg} / \mathrm{kg}$ before tourniquet inflation followed by its infusion at $1 \mathrm{mg} / \mathrm{kg} /$ hour till skin closure. Group $C$ received a similar amount of normal saline and served as the control group. The demographic data, duration of surgery, intraoperative vital parameters, intraoperative and postoperative blood loss, postoperative hemoglobin levels, quantity of blood transfusion required and a number of patients requiring blood transfusions and risk of the thromboembolic phenomenon were studied.

Results: The mean $( \pm S D)$ total blood loss was lower in the group receiving tranexamic acid $(306.96 \pm 75.23 \mathrm{~mL})$ than in control group ( $543 \pm 163.36 \mathrm{~mL}$ ) which amounted to $43.47 \%$ less blood loss in the group receiving tranexamic acid. On an average control group required six times more blood transfusion than tranexamic acid group.

Conclusion: Use of intravenous tranexamic acid is an effective and safe method to decrease blood loss in surgeries on the bone like total knee replacement.

\footnotetext{
${ }^{1}$ Additional Professor, ${ }^{2}$ Ex-resident

1,2Department of Anesthesiology, Seth GS Medical College and KEM Hospital, Mumbai, Maharashtra, India

Corresponding Author: Madhavi Buddhi, Additional Professor, Department of Anesthesiology, Seth GS Medical College and KEM Hospital, Mumbai, Maharashtra, India, e-mail: madhavi_70@yahoo.com
}

Keywords: Blood loss, Blood transfusion, Total knee replacement, Tranexamic acid.

How to cite this article: Buddhi M, Kapadia D. Efficacy and Safety of Tranexamic Acid in Total Knee Replacement Surgeries: A Randomized Control Trial. Res Inno in Anesth 2018;3(2):37-40.

Source of support: Nil

Conflict of interest: None

\section{INTRODUCTION}

Subjecting patients to major orthopedic surgical procedures like hip and knee replacement and spine surgeries invariably results in significant intraoperative and postoperative bleeding due to dissection through highly vascular bones and inability to cauterize bleeding osseous tissue. Use of techniques such as tourniquet application to reduce blood loss can also aggravate fibrinolysis. ${ }^{1,2}$ The coagulation cascade triggered due to vascular damage and tissue trauma leads to fibrin deposition aiding in the formation of the clot which prevents blood loss. Simultaneously, the fibrinolytic system comes into play to maintain the fluidity of blood; by way of activation of plasminogen by tissue plasminogen activator ( $t-P A)$ released from endothelial cells. Plasminogen binds to lysine residues on the surface of fibrin and is converted to plasmin which is an active proteolytic enzyme. Plasmin lysis fibrin into soluble fibrin degradation product resulting in the breakdown of the newly formed clots. Plasmin also has a part in the development of inflammation as it activates neutrophils, monocytes and triggers the complement system. ${ }^{3,4} \mathrm{TAX}$ is a synthetic analog of amino acid lysine, which has antifibrinolytic effects through temporary blockade of lysine-binding sites on plasminogen making it less efficient in the degradation of fibrin and thus slowing down the degradation of protective clots. ${ }^{5,6}$

This is a study to evaluate the efficacy and safety of TAX in reducing blood loss and postoperative blood transfusions following total knee replacement. In this study, we have used $10 \mathrm{mg} / \mathrm{kg}$ intravenous bolus of tranexamic acid before tourniquet inflation followed by $1 \mathrm{mg} / \mathrm{kg} /$ hour infusion throughout the surgery.

\section{MATERIALS AND METHODS}

With institutional ethics committee approval and written informed consent, 60 patients (ASA grade I/II patients 
between 18 years and 70 years, undergoing surgery for the total knee replacement were included. Patients with a history of allergy to medications, bleeding disorders, abnormal coagulation studies, contraindications to spinal-epidural anesthesia, impaired renal or hepatic function, pregnancy or lactation, history of thromboembolic episodes, history of ocular pathology or intraocular procedure were excluded from the study. Patients were allocated through computer randomization to either of two groups of 30 each.

\section{Group T (Tranexamic Acid)}

Patients received intravenous bolus tranexamic acid 10 $\mathrm{mg} / \mathrm{kg}$ followed by infusion at $1 \mathrm{mg} / \mathrm{kg} /$ hour.

\section{Group C (Placebo/Control)}

Patients received an intravenous bolus of normal saline at $1 \mathrm{~mL} / \mathrm{kg}$ followed by infusion at $1 \mathrm{mg} / \mathrm{kg} /$ hour.

All patients underwent a preanesthetic assessment including preoperative hemoglobin concentration and coagulation profile. Premedication with ranitidine 50 mg IV and ondansetron $4 \mathrm{mg}$ IV was done just before surgery. In the operation theatre, monitoring was started with cardioscope for electrocardiogram (ECG), oxygen saturation with pulse oximetry (SPO2) and noninvasive blood pressure (NIBP) measurement. Warm ringer lactate was used for intravenous fluid. All patients were given spinal-epidural anesthesia with intrathecal hyperbaric $0.5 \%$ bupivacaine dose $15-20 \mathrm{mg}$. Postoperative analgesia was provided through an epidural catheter. All patients were given supplemental oxygen at 4-6 L per minute via a Hudson mask.

Blinding for the drug used was ensured for the anesthesiologist, surgeon as well as the observer recording the findings. Throughout the study, a senior anesthetist not directly involved prepared the randomly allotted drug or placebo which was administered just before tourniquet inflation. The patients received either $20 \mathrm{~mL}$ slow intravenous bolus of tranexamic acid $10 \mathrm{mg} / \mathrm{kg}$ followed

Table 1: Demographic profile and duration of surgery in tranexamic acid group and control group

\begin{tabular}{llll}
\hline & Group T & Group C & $p$ value \\
\hline $\mathrm{n}=30$ & & & \\
$\mathrm{~N}=30$ & & & \\
Age (years) & $59 \pm 10.050$ & $59 \pm$ & 0.923 \\
& & 8.267 & \\
Gender (M/F) & $17 / 13$ & $14 / 16$ & 0.795 \\
Weight (kg) & $65.53 \pm 7.7$ & $69.47 \pm$ & 0.73 \\
& & 8.963 & \\
Duration of & $133.82 \pm$ & $135 \pm 8.633$ & 0.466 \\
surgery (minutes) & 9.491 & & \\
\hline
\end{tabular}

Data is displayed as mean \pm SD. $p$ value $<0.05$ is statistically significant by infusion at $1 \mathrm{mg} / \mathrm{kg} /$ hour or $20 \mathrm{~mL}$ normal saline followed by infusion at $1 \mathrm{~mL} / \mathrm{kg} /$ hour. Vital parameters including pulse rate, mean arterial blood pressure and oxygen saturation were noted at regular intervals, before and after tourniquet inflation, after tourniquet deflation till 24 hours postoperatively. Blood loss was measured at the end of the surgery, after 4 hours and at 24 hours postoperatively at the time of drain removal. Postoperative hemoglobin levels at 4 hours and 24 hours were measured. The criteria for blood transfusion was a fall in hemoglobin level below $8 \mathrm{gm} \%$. A number of transfusions of packed red cells required and any thromboembolic or other complications were noted.

\section{Statistical Analysis}

The data were entered using Microsoft Excel and analyzed using statistical package for social sciences (SPSS) version 21 software. Appropriate statistical tests like an unpaired t-test (For comparison of mean between two groups for normally distributed data), Chi-square test (for comparison of proportions between two groups) are used as per the data. Power analysis suggested that at least 25 patients should be included in each group considering alpha risk (false positive) at $5 \%$ and beta-risk (false negative) of $5 \%$ and power desired is $95 \%$. Considering a $10 \%$ dropout rate 30 patients fulfilling the inclusion and exclusion criteria were included in each group. The $p$ value less than 0.05 was taken as significant.

\section{OBSERVATION AND RESULTS}

There was no significant difference in the demographic data between group T (TAX) and group C (control) (Table 1). The preoperative hemoglobin levels, duration of surgery was comparable in the two groups (Tables 1 and 2 and Graph 1).

The vital parameters measured were similar in both the groups throughout the study (Table 3 and Graphs 2 and 3) however in the control group there was a significant difference in the preoperative hemoglobin (11.6 \pm $0.79 \mathrm{gm} \%$ ) and postoperative hemoglobin levels (10.28 \pm

Table 2: Preoperative and postoperative hemoglobin levels in tranexamic acid group and control group

\begin{tabular}{|c|c|c|c|}
\hline & Group $T$ & Group C & $p$ value \\
\hline $\begin{array}{l}\text { Preoperative } \mathrm{Hb} \\
\text { (gm/dL) }\end{array}$ & $\begin{array}{l}11.66 \pm \\
0.806\end{array}$ & $\begin{array}{l}11.60 \pm \\
0.796\end{array}$ & 0.797 \\
\hline $\begin{array}{l}\text { Postoperative Hb } \\
\text { (gm/dL) (at } 4 \\
\text { hours) }\end{array}$ & $\begin{array}{l}11.418 \pm \\
0.7902\end{array}$ & $\begin{array}{l}10.930 \pm \\
1.005\end{array}$ & 0.046 \\
\hline $\begin{array}{l}\text { Postoperative } \mathrm{Hb} \\
\text { (gm/dL) (at } 24 \\
\text { hours) }\end{array}$ & $\begin{array}{l}11.153 \pm \\
0.8443\end{array}$ & $\begin{array}{l}10.287 \pm \\
1.3059\end{array}$ & 0.003 \\
\hline
\end{tabular}

Data is displayed as mean \pm SD. $p$ value $<0.05$ is statistically significant 
Table 3: Pulse rate and mean arterial pressure in tranexamic acid group and control group

\begin{tabular}{|c|c|c|c|c|c|c|}
\hline & \multicolumn{2}{|c|}{ Group $T$} & \multicolumn{2}{|c|}{ Group C } & \multicolumn{2}{|c|}{$p$ value } \\
\hline & $\begin{array}{l}\text { Pulse rate } \\
\text { (bpm) }\end{array}$ & MAP $(\mathrm{mm} \mathrm{Hg})$ & $\begin{array}{l}\text { Pulse rate } \\
\text { (bpm) }\end{array}$ & MAP $(\mathrm{mm} \mathrm{Hg})$ & Pulse rate & MAP \\
\hline Preoperative & $75.33 \pm 6.733$ & $83.97 \pm 9.028$ & $75.47 \pm 6.627$ & $84.63 \pm 6.430$ & 0.939 & 0.743 \\
\hline Before tourniquet deflation & $66.60 \pm 5.630$ & $77.51 \pm 7.998$ & $66.93 \pm 7.900$ & $77.73 \pm 6.400$ & 0.851 & 0.905 \\
\hline After tourniquet deflation & $76.64 \pm 7.752$ & $76.66 \pm 7.287$ & $82.83 \pm 7.091$ & $75.80 \pm 7.092$ & 0.002 & 0.650 \\
\hline End of surgery & $74.57 \pm 6.779$ & $78.93 \pm 8.419$ & $75.00 \pm 5.414$ & $78.53 \pm 5.752$ & 0.791 & 0.834 \\
\hline Postoperative (at 4 hours) & $72.93 \pm 5.477$ & $80.50 \pm 7.456$ & $74.93 \pm 5.278$ & $79.83 \pm 5.867$ & 0.161 & 0.706 \\
\hline Postoperative (at 24 hours) & $73.93 \pm 5.944$ & $81.71 \pm 7.958$ & $73.80 \pm 5.385$ & $80.63 \pm 6.605$ & 0.931 & 0.575 \\
\hline
\end{tabular}

Data is displayed as mean \pm SD. $p$ value $<0.05$ is statistically significant

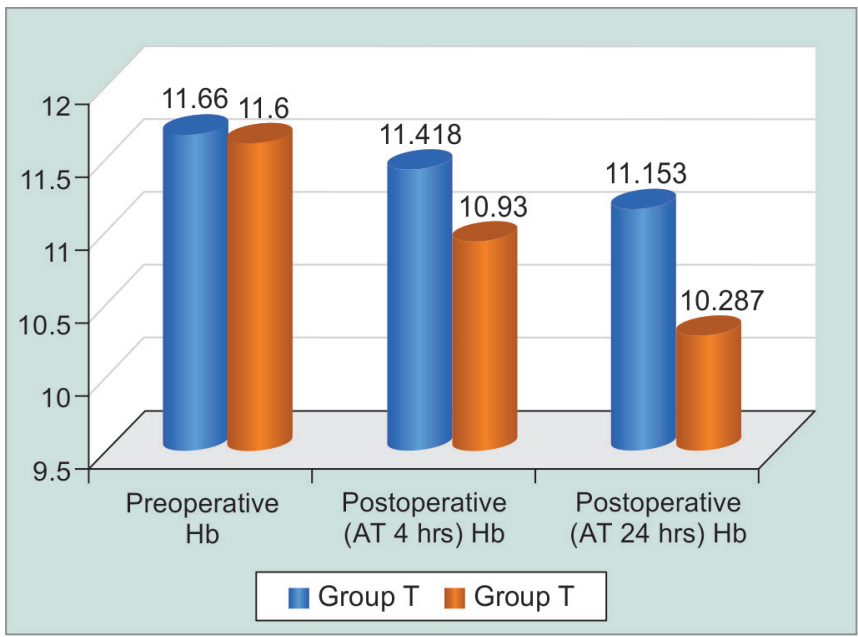

Graph 1: Comparison of preoperative and postoperative hemoglobin ( $\mathrm{gm} / \mathrm{dL})$ (mean) levels in tranexamic acid group and control group

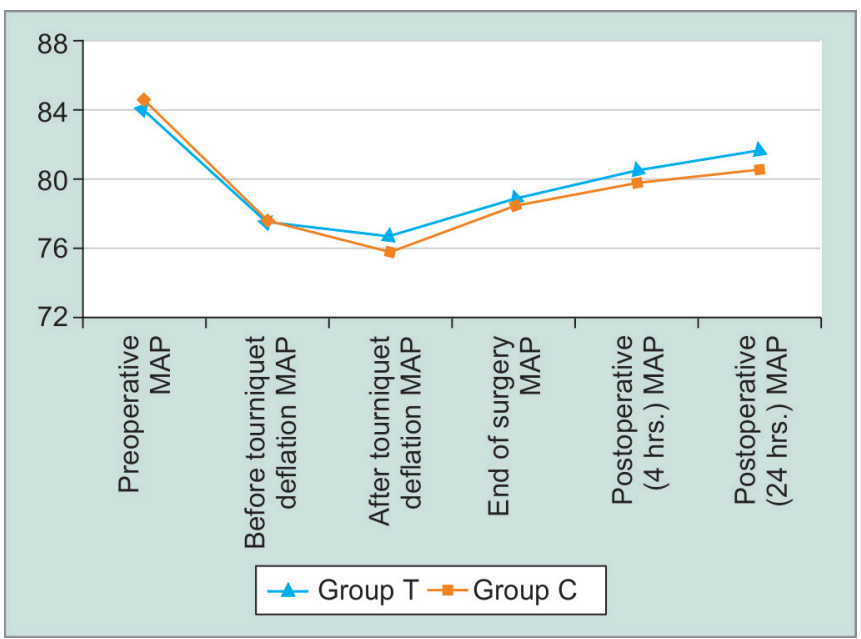

Graph 3: Comparison of mean arterial pressure $(\mathrm{mm}$ of $\mathrm{Hg})$ at regular intervals in tranexamic acid group and control group

$1.3 \%)(p$ value 0.03$)$ (Graph 1). The difference in mean total blood loss in tranexamic acid $(306.96 \pm 75.23 \mathrm{~mL})$ and the control group $(543 \pm 163.36 \mathrm{~mL})$ was statistically different ( $p$ value 0.0001 ) (Table 4 and Graph 4 ). Only one patient in TAX required one bag of red blood cell transfusion, but in the control group, six patients required transfusion of one bag each which is a significant reduction in need of blood requirement. There was no incidence of a

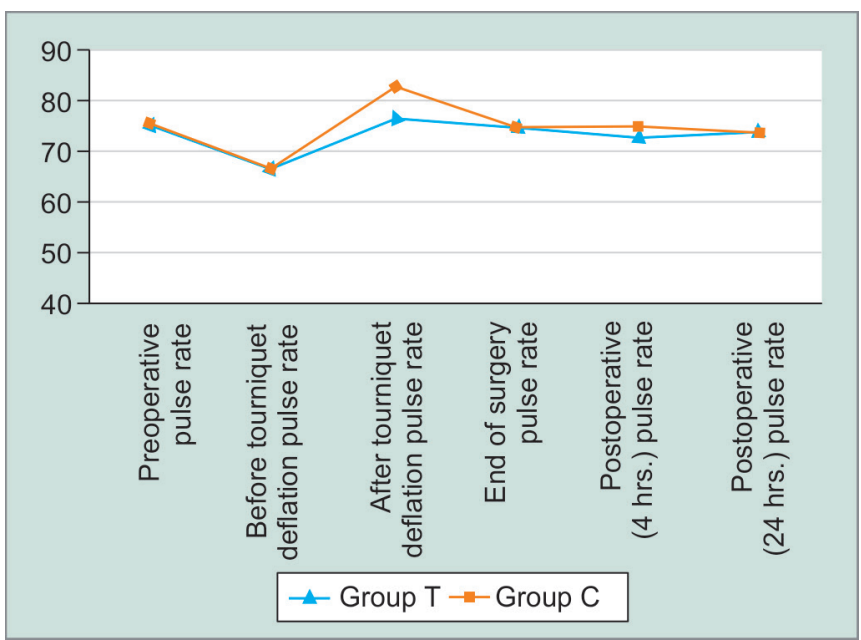

Graph 2: Comparison of pulse rate(beats per minute) (mean) at regular intervals in tranexamic acid group and control group

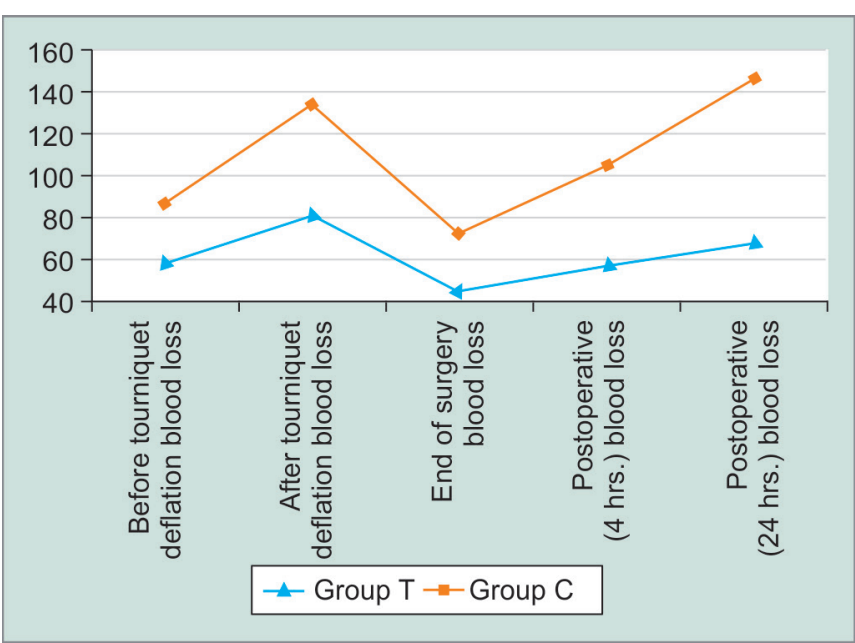

Graph 4: Comparison of blood loss in $\mathrm{mL}$ (mean) at regular intervals in tranexamic acid group and control group

Table 4: Blood loss in millilitres in tranexamic acid group and control group

\begin{tabular}{llll}
\hline & Group $T$ & Group C & $p$ value \\
\hline Total blood & $306.96 \pm$ & $543.00 \pm$ & 0.001 \\
loss (in mL) & 75.232 & 163.362 & \\
\hline
\end{tabular}

Data is displayed as mean \pm SD. $p$ value $<0.05$ is statistically significant

thromboembolic phenomenon or other relevant complications in either group. 


\section{DISCUSSION}

Total knee replacement surgery (TKR) is one of the common orthopedic surgeries in recent times involving significant bleeding from the bone surfaces as well as fibrinolysis due to surgery and tourniquet. The blood loss is quite significant especially postoperatively and also requires a blood transfusion if not controlled. Blood transfusion itself has a number of complications. ${ }^{7}$ Tranexamic acid (trans-4-(aminomethyl) cyclohexane carboxylic acid) has gained popularity as an antifibrinolytic in reducing perioperative blood loss thus avoiding blood transfusions. The therapeutic effect of tranexamic acid is due to its ability to support the formation of a more stable fibrin clot by preventing its early degradation by the proteolytic enzyme plasmin. ${ }^{8}$

We have designed this double-blinded randomized control study to evaluate the efficacy and safety of tranexamic acid in total knee replacement surgery. Sixty patients of ASA I and ASA II status undergoing unilateral TKR surgeries were divided into two groups of 30 each, group $\mathrm{T}$ (study) and group C (control). We have demonstrated that tranexamic acid $10 \mathrm{mg} / \mathrm{kg}$ IV before tourniquet inflation followed by infusion $1 \mathrm{mg} / \mathrm{kg} / \mathrm{hour}$ till skin closure can produce a decrease in blood loss by $43.47 \%$. This resulted in lesser number of transfusions and its associated complications as well as optimizing the use of limited health sources.

Kakar et al. studied the efficacy and safety of tranexamic acid in a double-blinded study in total knee replacement surgeries found that postoperative blood loss, transfusion requirement, and fall in hemoglobin was less with the use of tranexamic acid, and also costeffective with fewer complications. ${ }^{9}$

Almeida et al. evaluated the efficacy of tranexamic acid in reducing bleeding in patients undergoing total knee arthroplasty in a triple blinded study prospective randomised controlled study and found that despite their study group having significant lower hemoglobin and hematocrit levels (in the preoperative period) than the control group, the fall in hemoglobin and blood loss was significantly more in the control group. ${ }^{10}$

Vijay et al. studied the role of tranexamic acid in the context of a pharmacological agent to reduce postoperative blood loss and transfusion requirements in patients undergoing hip and femoral surgeries and concluded that administration of tranexamic acid preoperatively reduced the blood loss in the first 24 hours by highly significant degree in patients undergoing surgeries for hip and femoral fractures. ${ }^{11}$

In a review article titled "Tranexamic acid and orthopaedic surgery - the search for the holy grail of blood conservation", Danninger et al. have analysed major trials on tranexamic acid use in orthopaedic surgeries and concluded that there is substantial evidence suggesting tranexamic acid is effective in reducing blood loss and the need for blood transfusion in orthopedic surgeries involving joints. Clinical data proving the perioperative safety and efficacy oftranexamic acid are becoming evident and look promising. Yet, they have expressed concern regarding groups at risk for thromboembolic complications and acknowledged the need for more research. ${ }^{12}$

\section{CONCLUSION}

It is concluded from our study that tranexamic acid is an efficacious and safe antifibrinolytic which helps in reducing blood loss and need of blood transfusions and their associated complications in TKR surgeries without any significant adverse reactions.

\section{REFERENCES}

1. Mannucci PM, Levi M. Prevention and treatment of major blood loss. N Engl J Med 2007;356:2301-2311.

2. Sculco TP. Global blood management in orthopedic surgery. Clin Orthop Relat Res 1998;357:43-49.

3. Zimmerman LH. Causes and consequences of critical bleeding and mechanism of blood coagulation. Pharmacotherapy 2007;27:45S-56S.

4. Benoni G, Fredin H. Fibrinolytic inhibition with tranexamic acid reduces blood loss and blood transfusion after knee arthroplasty. A prospective, randomised, double-blind study of 86 patients. J Bone Joint Surg [Br] 1996; 78-B:434-440.

5. Vera-Llonch M. Clinical and economic consequences of bleeding following major orthopedic surgery. Thrombosis Research 2006;117:569-577.

6. Lozano C. Tranexamic acid reduces allogenic red cell transfusions in patients undergoing total knee arthroplasty: results of a meta-analysis of randomized controlled trials. Transfusion 2005;45:1302-1307.

7. Melanie J Maxwell, Mathew JA Wilson. Complications of blood transfusion. Continuing Education in Anaesthesia Critical Care \& Pain, 2006;6(6):1:25-229.

8. Eriksson BI, Eriksson E, Risberg B. Impaired fibrinolysis and postoperative thromboembolism in orthopaedic patients. Thromb Res 1991;62:55-64.

9. Kakar PN, Gupta N, Govil P, et al. Efficacy and Safety of tranexamic Acid in Control of Bleeding Following TKR. Indian J Anaesth 2009;53:667-671.

10. Almeida MD, Albuquerque RP, Palhares GM, et al. Evaluation of the use of tranexamic acid in total knee arthroplasty. Rev Bras Ortop 2018;53(6):761-767. ISSN0102-3616

11. Vijay BS, Bedi V, Mitra S, et al. Role of Tranexamic acid in reducing postoperative blood loss and transfusion requirement in patients undergoing hip and femoral surgeries. Saudi J Anaesth 2013;7(1);29-32.

12. Danninger T, Stavros G. Memtsoudis Tranexamic acid and orthopaedic surgery-the search for the holy grail of blood conservation. Ann Transl Med 2015;3(6);77. 